\title{
Heterogeneous photo-Fenton oxidation with natural clays for phenol and tyrosol remediation
}

\author{
L. Djeffal ${ }^{1,2,3}$, S. Abderrahmane ${ }^{1}$, M. Benzina ${ }^{4}$, S. Siffert ${ }^{2,3}$ and S. Fourmentin ${ }^{2,3}$ \\ ${ }^{1}$ Laboratoire d'Ingénierie des Surfaces, Université Badji-Mokhtar, Annaba, Algérie \\ 2 Univ. Lille Nord de France, 59000 Lille, France \\ 3 ULCO, UCEIV EA4492, 59140 Dunkerque, France \\ ${ }^{4}$ Laboratoire «Eau, Énergie et Environnement» (LR3E), ENIS, Université de Sfax, Tunisie
}

\begin{abstract}
Due to their excellent properties, clays have been widely used in several applications, particularly in catalysis. In this paper, three clays were used as heterogeneous photo-Fenton catalysts for phenol and tyrosol oxidations. Particular attention was given to the effect of the main operating conditions on the process performance. A total conversion was obtained for both organic pollutants with studied catalysts in 20 minutes reaction. For phenol, a total organic carbon (TOC) conversion of $93 \%$ was obtained using sieved and calcined smectite clay. The TOC conversion was $60 \%$ for tyrosol with the same catalyst. Clays were characterized by chemical analysis, BET, XRD, TPR and SEM.
\end{abstract}

\section{INTRODUCTION}

Photo Fenton process has been widely studied as promising way to treat various kinds of organic wastewater $[1,2]$. The most important reaction pathway of this process includes the photo reduction of $\mathrm{Fe}^{3+}$ to $\mathrm{Fe}^{2+}$ and subsequent reoxidation of $\mathrm{Fe}^{2+}$ to $\mathrm{Fe}^{3+}$ by $\mathrm{H}_{2} \mathrm{O}_{2}$. At the same time, the hydroxyl radical $\left(\mathrm{OH}^{-}\right)$is generated, it is considered as dominant species with the potential ability to oxidize most of organic contaminants into carbon dioxide and water [3]. Heterogeneous photoFenton process, in which the catalysts can be easily reused after wastewater treatment and avoid the possible additional metal pollution, is considered as the most efficient. Clays, both natural and chemically modified are attractive materials as catalysts supports [4]. Due to their wide utilization in several industries, phenols have become the most abundant pollutant in wastewater. In this paper, we investigated the use of three natural clays from Algeria and Tunisia, as catalysts in the photo-Fenton oxidation of phenol and tyrosol.

\section{MATERIALS AND METHODS}

\subsection{Materials}

Phenol (99\%), $\mathrm{H}_{2} \mathrm{O}_{2}(30 \mathrm{wt} \%)$ of analytical reagent grade (Aldrich), Tyrosol (98\%, ACROS Organics), acetonitrile and water of HPLC grade (Panreac) were used without further purification.

The first clay (Smectite) was sampled in Jebel TejeraEsghira (Tunisian Southweast), the second one (Bentonite) sampled in Hammam- Boughrara (Algerian northwest) and Kaolin clay from Hamman Debagh-Guelma (Algerian northeast).

\subsection{Catalyst characterization}

The chemical composition of the clay was determined by X-ray fluorescence with an ARL $(9800$ XP spectrometer.
The temperature programmed reduction (TPR) profiles were recorded from 25 up to $900^{\circ} \mathrm{C}$ at a heating rate of $5^{\circ} \mathrm{min}^{-1}$ in a flow of $5 \% \mathrm{H}_{2} / \mathrm{Ar}\left(30 \mathrm{~mL} \mathrm{~min}^{-1}\right)$ using an Altamira AMI-200 apparatus. The specific surface area was determined by nitrogen adsorption at $77 \mathrm{~K}$ on a Qsurf M1 apparatus (Thermo Electron Corporation). Characterization by X-Ray diffraction (XRD) was done using a Philips ${ }^{\circledR}$ PW 1710 diffractometer $(\mathrm{Cu} \mathrm{K} \alpha$, $40 \mathrm{kV} / 40 \mathrm{~mA}$, scanning rate of $2 \theta$ per min). SEM analysis was realized by using MEB LEO 438VP.

\subsection{Catalytic degradation procedure}

Catalytic tests were performed in aqueous medium at ambient conditions (atmospheric pressure and at room temperature) in a thermostated perfectly stirred Pyrex reactor of $250 \mathrm{~mL}$. In each test the reactor was loaded with $100 \mathrm{~mL}$ of phenol or tyrosol solution $(0.5 \mathrm{mM})$ and $100 \mathrm{mg}$ of catalyst. $7 \mathrm{mM}$ or $10 \mathrm{mM}$ of hydrogen peroxide (30wt\%) was added to initiate the reaction in the case of phenol and tyrosol respectively (the theoretical initial concentration required for the entire mineralization of pollutant). High performance liquid chromatography (HPLC, Waters 600) and Shimadzu TOC-V $\mathrm{V}_{\mathrm{CSH}}$ analyzer were used to quantify residual amount of pollutants and TOC in reaction media. A low pressure UV lamp with wavelength of $254 \mathrm{~nm}$ (Heliosquartz, Italy) was used as light source and a Pyrex reactor.

\section{RESULTS AND DISCUSSION}

\subsection{Catalyst characterization}

Chemical analysis of raw clays (table 1) showed that solids were mainly composed of aluminum and silica oxides. smectite had particularly high iron oxide content (more than $12 \%$ ), compared with bentonite $(4.12 \%)$ and kaolin $(0.26 \%)$. Other oxides were also present in lower amounts. 
Table 1. Chemical composition and specific area of raw clays in $\mathrm{wt} \%$.

\begin{tabular}{lccccccc}
\hline & $\mathrm{SiO}_{2}$ & $\mathrm{Al}_{2} \mathrm{O}_{3}$ & $\mathrm{~K}_{2} \mathrm{O}$ & $\mathrm{MgO}$ & $\mathrm{CaO}$ & $\mathrm{Fe}_{2} \mathrm{O}_{3}$ & $\begin{array}{c}\mathrm{BET} \\
\left(\mathrm{m}^{2} \mathrm{~g}^{-1}\right)\end{array}$ \\
Smectite & 53.86 & 24.29 & 2.32 & 3.27 & 0.66 & 12.15 & 50 \\
Bentonite & 58.45 & 17.14 & 5.51 & 4.36 & 1.07 & 1.20 & 108 \\
Kaolin & 44.57 & 38.25 & 0.06 & 0.01 & 0.25 & 0.26 & 32 \\
\hline
\end{tabular}

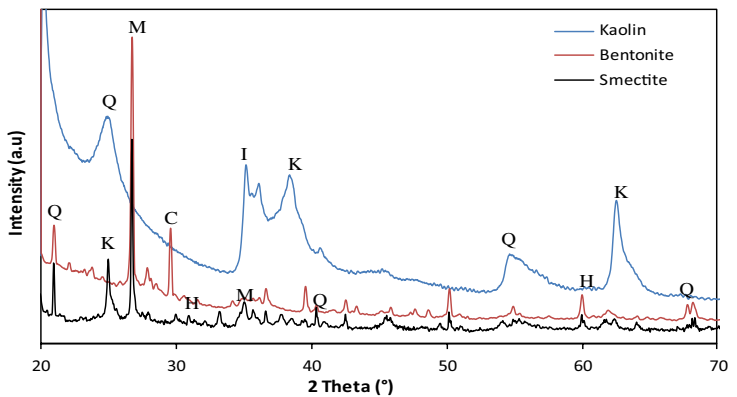

Figure 1. Powder X-ray diffraction of natural clays [Q: quartz, $\mathrm{M}$ : montmorilonite, $\mathrm{K}$ : kaolinite, $\mathrm{C}$ : calcite, $\mathrm{H}$ : hematite, I: illite].

The white shade of kaolin increases significantly with decreasing impurities which leads us to infer that the white kaolin that we used in this study contain very low impurities.

$\mathrm{X}$-ray diffraction analysis of natural clays (Figure 1) shows that the predominating minerals present in kaolin sample are kaolinite, halloysite, illite and quartz. The examination of the bentonite and smectite diffractograms reveals the presence of montmorillonite, illite, quartz, hematite and calcite.

The SEM analysis of kaolin sample, showed a mixture of fibrous and planar morphologies, with predominant presence of a tubular morphology characteristics of halloysite (Figure 2a). Inhomogeneous distribution of particle sizes with lamellar arrangement of grains was observed in bentonite shot (Figure 2b). For smectite sample, sheets constituent grains are well marked, therefore, a presence of particles of different sizes was also observed (Figure 2c).

Temperature programmed reduction analysis of the clays (Figure 3), showed that for smectite two stage reduction were observed: $\mathrm{Fe}_{2} \mathrm{O}_{3}$ was reduced to $\mathrm{Fe}_{3} \mathrm{O}_{4}$ and then reduced to metallic $\mathrm{Fe}[5,6]$. However a little peak near $460^{\circ} \mathrm{C}$ appeared in bentonite profile, this peak resulted from the reduction of $\mathrm{Fe}$ (III) to Fe (II) as referred by Iurascu et al. [6], two other little peaks appeared within $600-800^{\circ} \mathrm{C}$. No significant reduction was observed for kaolin. The high hydrogen consumption accorded to the smectite, can be attributed to the high iron content as confirmed by chemical analysis.

\subsection{Catalytic performance}

The $\mathrm{pH}$ of the medium is a crucial operating parameter, it affect directly the photo catalytic performance [8]. Two $\mathrm{pH}$ were chosen: 3 and 5 . Results obtained for the oxidation of phenol (Figure 4) shows that the higher $\mathrm{pH}$ led a higher phenol removal. More than $90 \%$ of phenol conversion was

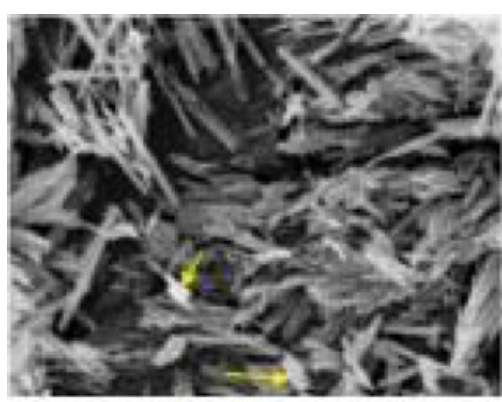

[a]

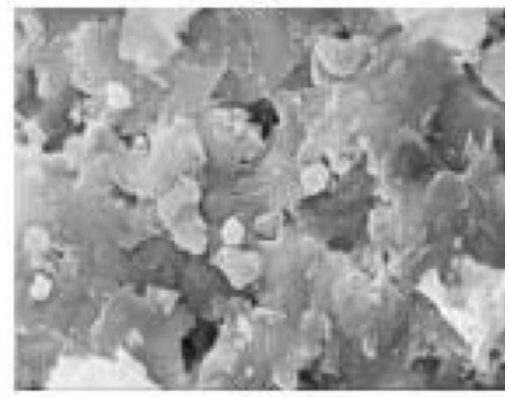

(b)

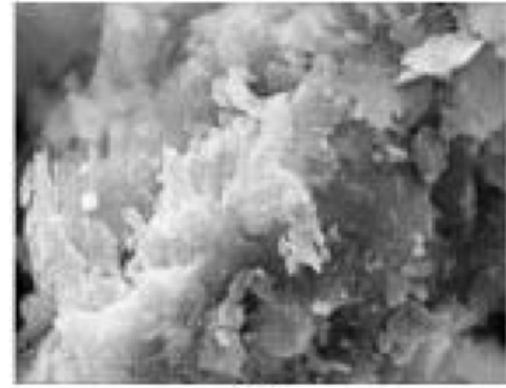

(c)

Figure 2. SEM shots of characterized clays (a): kaolin, (b): bentonite, (c): smectite.

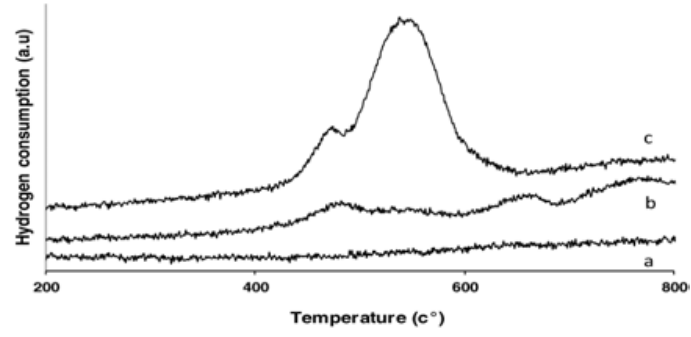

Figure 3. TPR profiles of clays [a: Kaolin, b: Bentonite, c: Smectite].

obtained after 20 minutes reaction in all cases. Similar results were obtained in tyrosol photo-Fenton oxidations at the same reaction conditions using raw clays.

The efficiency of catalysts can be really observed when we quantified the TOC abatement. We illustrated in Figure 5, the TOC abatement after phenol photo-Fenton oxidation's reaction.

We observe that for all catalysts, the TOC conversion was similar at pH5 (near 50\%), but for reactions realized at $\mathrm{pH} 3$, the highest percentage is attributed to smectite with $15 \%$ of TOC removal. In literature, for homogeneous 


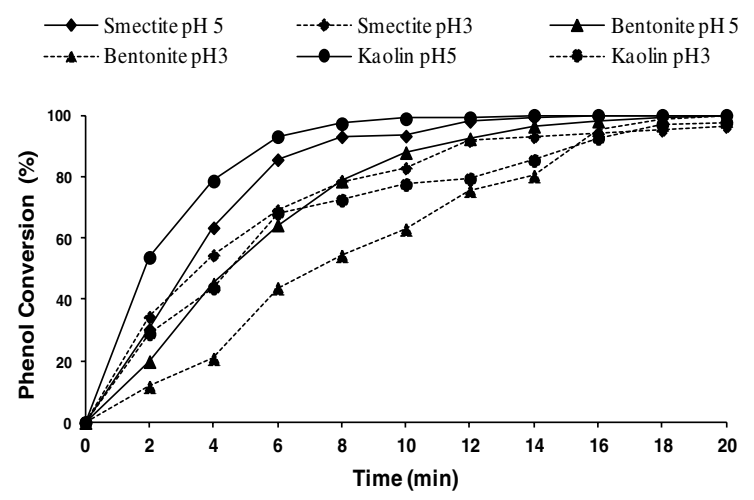

Figure 4. Effect of $\mathrm{pH}$ on the conversion of phenol ([phenol $]_{0}=$ $0.5 \mathrm{mmol},\left[\mathrm{H}_{2} \mathrm{O}_{2}\right]_{0}=7 \mathrm{mmol}, \mathrm{m}_{\text {catalyst }}=100 \mathrm{mg}$ ).

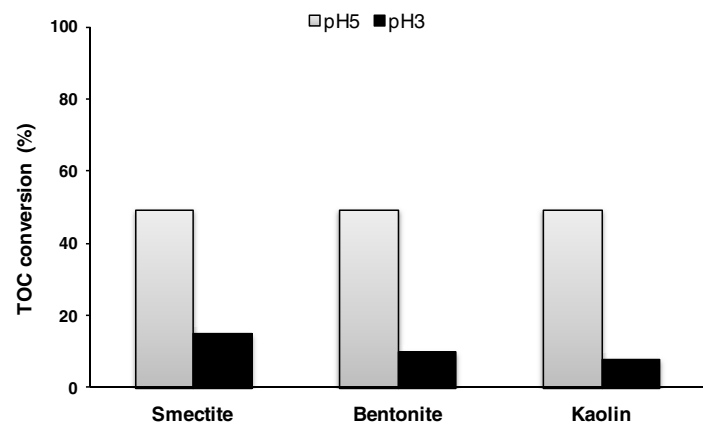

Figure 5. TOC abatement for phenol heterogeneous photoFenton oxidation $\left([\mathrm{phenol}]_{0}=0.5 \mathrm{mmol},\left[\mathrm{H}_{2} \mathrm{O}_{2}\right]_{0}=7 \mathrm{mmol}\right.$, $\mathrm{m}_{\text {catalyst }}=100 \mathrm{mg}$ ).

reaction, the optimal $\mathrm{pH}$ is being close 3 [9], because above this $\mathrm{pH}$ value, the formation of hydroxyl radicals slows down due to the hydrolysis of Fe(III) and precipitation of $\mathrm{FeOOH}$ from the solution [8]. In photo-Fenton oxidation of phenol at $\mathrm{pH} 3$ catalyzed by natural clays, the lowest conversions TOC rates were observed at $\mathrm{pH} 3$, this results can be attributed to the undesirable $\mathrm{H}_{2} \mathrm{O}_{2}$ degradation at this $\mathrm{pH}$ value [10]. In this study, the higher catalytic activity at $\mathrm{pH} 5$, can be from the fact that, the photolysis of hydrogen peroxide is favored by ultraviolet radiation [8], which promote the formation of more $\mathrm{OH}^{\bullet}$ and enhanced the mineralization of pollutant. The good catalytic activity when the $\mathrm{pH}$ is higher than 3, could also be explained by the decrease of the $\mathrm{pH}$ along the oxidation [11]. This $\mathrm{pH}$ change, results from the formation of acidic intermediates and products. Indeed succinic, malonic, oxalic acids have been detected during degradation of phenol and phenolic compounds [12]. Obtained results are in full agreement with others researches indicating that the photo-Fenton treatment of wastewaters without adjusting their $\mathrm{pH}$ might also become feasible, because industrial organic contaminated wastewaters often have $\mathrm{pH}$ around 7 [13].

We chose to use the smectite in the following of this work for its catalytic performance in TOC removal during the degradation of both pollutants. Study of the effect of particles size and calcination's temperature of smectite on it's catalytic activity (not shown in this paper), showed that the optimal particle size and calcinations' temperature

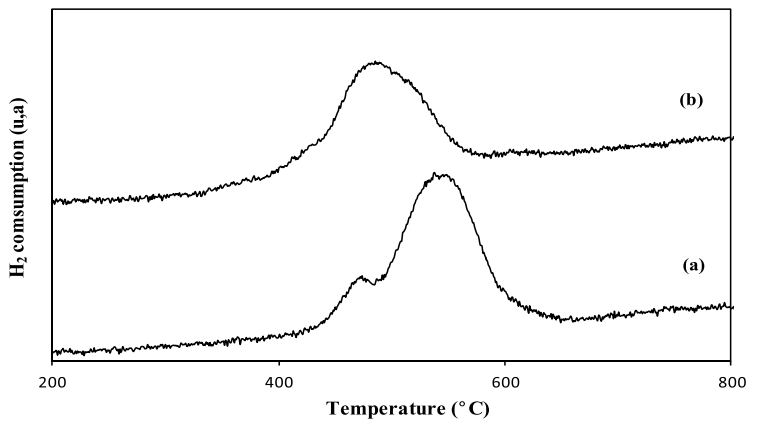

Figure 6. TPR profiles of raw smectite (a) and S-50-450 (b).

were respectively $50 \mu \mathrm{m}$ and $450^{\circ} \mathrm{C}$. The use of sieved and calcined smectite for the photo-Fenton oxidation gives $93 \%$ of TOC conversion for phenol and $60 \%$ for tyrosol with the same catalyst.

Compared to the TPR profile of raw smectite, sieved and calcined smectite (S-50-450) (Figure 6) showed a shift of the reduction peak towards lower temperatures.

This result leads us to assume that the improvement in catalytic performance is due to the fact that iron in S-50450 catalyst is reduced more easily, which allows it to react with the hydrogen peroxide present in solution to produce more hydroxyl radicals.

\section{CONCLUSION}

This study on the oxidative efficiency of clays as catalysts in heterogeneous photo-Fenton reaction for phenol and tyrosol removal, shows that the use of those natural catalysts presents several advantages with respect to the environment. It leads to higher removal percentage of pollutants and total organic carbon at mild operating conditions. A simple modification of the raw clay like calcination and sieving can provide excellent results achieving $93 \%$ of TOC removal for phenol.

The authors are grateful to PHC Maghreb ${ }^{\circ}$ 27959PD for financial support.

\section{References}

[1] J. García-Montaño, F. Torrades, J.A. García-Hortal, X. Domènech, J. Peral, Appl.Catal B, 67, 86-92 (2006).

[2] J.M. Monteagudo, M. Carmona, A. Duran, Chemosphere. 60, 1103-1110 (2005).

[3] J. Chen, L. Zhu, Sep. Purif. Technol., 67, 282-288 (2009).

[4] A. Gill, S.A. Korili, M.A. Vicente, Catal. Rev. Sci. Eng. 50, 153-221 (2008).

[5] M.J. Tiernan, P.A. Barnes, G. Parkes, J. Phys. Chem. B. 105, 220-228 (2001).

[6] B. Iurascu, I. Siminiceanu, D. Vione, M.A. Vicente, A. Gil, Water Res. 43, 1313-1322 (2009).

[7] H.Y. Lin, Y.W. Chen, C. Li, Thermochim. Acta. 400, 61-67 (2003). 
[8] J. Herney-Ramirez, M.A. Vicente, L.M. Madeira, Appl Catal., B, 98, 10-26 (2010).

[9] J. Feng, X. Hu, P.L. Yue. Water Res. 40, 641-646 (2006).

[10] W. Najjar, S. Azabou, S. Sayadi, A. Ghorbel, Appl. Catal. B. 74, 11-18 (2007).
[11] J. Feng, R.S.K. Wong, X. Hu, P.L. Yue, Catal. Today, 98, 441-446 (2004).

[12] X.Y. Li, Y.H. Cui, Y.J. Feng, Z.M. Xie, J.D. Gu, Water Res. 39, 1972-1981 (2005).

[13] A.C.K. Yip, F.L.Y. Lam, X. Hu, Ind. Eng. Chem. Res. 44, 7983-7990 (2005). 